\title{
The Economic Promise of Delayed Aging
}

\author{
Dana Goldman \\ USC Schaeffer Center for Health Policy and Economics, University of Southern California, \\ Los Angeles, California 90089 \\ Correspondence: dpgoldma@usc.edu
}

Biomedicine has made enormous progress in the last half century in treating common diseases. However, we are becoming victims of our own success. Causes of death strongly associated with biological aging, such as heart disease, cancer, Alzheimer's disease, and stroke-cluster within individuals as they grow older. These conditions increase frailty and limit the benefits of continued, disease-specific improvements. Here, we show that a "delayed-aging" scenario, modeled on the biological benefits observed in the most promising animal models, could solve this problem of competing risks. The economic value of delayed aging is estimated to be $\$ 7.1$ trillion over 50 years. Total government costs, including Social Security, rise substantially with delayed aging — mainly caused by longevity increases - but we show that these can be offset by modest policy changes. Expanded biomedical research to delay aging appears to be a highly efficient way to forestall disease and extend healthy life.

M oonshot" was the word Google founder and chief executive officer Larry Page used to describe Calico- a biotech startup focused on the challenge of aging and age-associated pathology. In fact, the chances of success may be much greater.

Through rapid advances in biological research and medical innovation, the biomedical industry has made enormous strides in improving the health and lengthening the lives of Americans as a whole. Life expectancy at birth has risen from age 70 in 1960 to $\sim 79$ in 2015. The innovations in health care over the course of the century have led to a rapid drop in infant mortality. Fewer are dying from heart disease. Cancer survival rates are increasing. On the horizon, we see advances in medicine, genetics, and biomedical technology that may take us to new heights in slowing aging, preventing inherited diseases, and solving the health riddles that currently stump us.

These advances will leave the nation with an older society as more people live into their $80 \mathrm{~s}$, $90 \mathrm{~s}$, and even the 100s, and as the baby boomers enter old age. The potential costs of an aging society are well known, including rising health care costs at a time of shrinking government budgets. The solvency of Medicare is a perennial issue. Yet, thanks to health care and other advances, the health of the elderly population has also improved. In but one example, the nursing home population has declined along with disability rates. In $1985,5.4 \%$ of the elderly were in nursing homes. By 1995, the share was down to $4.6 \%$, on an age-adjusted basis (Cutler 2001).

Editors: S. Jay Olshansky, George M. Martin, and James L. Kirkland

Additional Perspectives on Aging available at www.perspectivesinmedicine.org

Copyright (C) 2016 Cold Spring Harbor Laboratory Press; all rights reserved; doi: 10.1101/cshperspect.a025072

Cite this article as Cold Spring Harb Perspect Med 2016;6:a025072 
D. Goldman

If advances in science and health care continue, people may continue to reach older ages as healthier and more active individuals (Lowsky et al. 2013). As a result, they may work longer and use fewer health care resources, while continuing to give back to society in numerous ways.

\section{THE ROLE OF TECHNOLOGY}

The specter of an aging society regularly ignites debate in health policy circles on costs versus benefits. Is it right, some wonder, that older adults in their last years of life consume 24\% of Medicare's expenditures? Or is it cost-effective to pay for a cancer treatment drug that will prolong an inevitable death for only a few months? In Britain, for example, the National Institute for Health and Clinical Excellence determines what therapies the National Health Service will cover. It generally recommends against paying for a therapy that costs more than $\$ 31,000$ to $\$ 47,000$ for each year of life gained, adjusted for quality.

Yet medical advances, although costly, are proving worth it in many instances, according to a vast body of research on cost effectiveness of medical care. There is good evidence that the benefits of health improvements dominate any additional costs for most new technologies. For example, life expectancy increased $\sim 7 \mathrm{yr}$ from 1960 to 2000 in most developed nations. During that span, the increases in medical spending have provided reasonable value, with the exception of spending increases in medical care for the elderly since 1980 .

Even in some of the most difficult diseases, we have made good progress (Goldman et al. 2005; Shekelle et al. 2005). Cancer is a salient example, as the policy debates about cancer costs are frequently most pronounced (Experts in Chronic Myeloid Leukemia 2013). Many say we are losing the war on cancer that Richard Nixon first declared in 1971. After all, cancer is the second leading cause of death, and accounts for approximately one-fourth of all deaths in a year. However, the reality is much more positive. Today, cancer patients live longer, healthier, and happier lives than those in prior decades.
Survival rates for all cancers increased by almost 4 years from 1988 to 2000 , creating 23 million additional life-years and generating $\$ 1.9$ trillion in additional value to society, once the health gains are tallied (Lakdawalla et al. 2010; Sun et al. 2010; Goldman and Philipson 2014; Stevens et al. 2015). Survival rates have continued to improve in recent years. Compared with research and development spending-both private and public — one can easily see a substantial return on investment. Furthermore, progress is being made in dealing with the extreme toxicity of chemotherapy and radiation regimens (Hsu et al. 2013). So, although cancer still remains a pernicious disease, there is hope that it can eventually be managed as a chronic illness with modest side effects.

\section{THE CHALLENGES OF THE SINGLE-DISEASE MODEL}

In some ways though, we are becoming victims of our own success. Increased disability rates are now accompanying increases in life expectancy, leaving the length of a healthy life span unchanged (Bhattacharya et al. 2004; Lakdawalla et al. 2004, 2010; Crimmins and BeltranSanchez 2011) or even shorter than in the past (Hulsegge et al. 2014). As people age, they are now much less likely to fall victim to a single isolated disease than was previously the case. Instead, competing causes of death more directly associated with biological aging (e.g., heart disease, cancer, stroke, Alzheimer's, etc.) cluster within individuals as they reach older ages. These conditions elevate mortality risk, as well as create the frailty and disabilities that can accompany old age.

Fortunately, new research is emerging that has the potential to extend life while reducing the prevalence of comorbidities over the entire lifetime (Kirkland 2013; Tchkonia et al. 2013). Scientists have been asking whether we can decelerate the process by which the cluster of conditions described above arises, making people healthier at older ages and even lowering spending on health care (Fries 1980; Fries et al. 1993; Miller 2002; Martin et al. 2007; Butler et al. 2008; Sierra et al. 2009; Tchkonia et al. 2013). 
Simply put, can we age more slowly-thereby delaying the onset and progression of all fatal and disabling diseases simultaneously?

At the practical level, delayed aging means having the body and mind of someone who is years younger than the majority of today's population at one's chronological age and spending a larger proportion of one's life in good health and free from frailty and disability (Fries 1980; Vergara et al. 2004; Butler et al. 2008). Experimental studies involving animal models have already succeeded in accomplishing this in the laboratory (Miller 2002), and this collection is filled with the latest research developments in aging science, suggesting that a therapeutic intervention to delay aging is on the horizon. In addition, there is evidence that centenarians (whose longevity is at least partially heritable) often have delayed onset of age-related diseases and disabilities, which suggests that they senesce (grow old biologically) more slowly than the rest of the population (Lipton et al. 2010).

By manipulating genes, altering reproduction, reducing caloric intake, modulating the levels of hormones that affect growth and maturation, and altering insulin-signaling pathways, it has been possible to extend the life span-and the healthy life span-of invertebrates and mammals (Tatar et al. 2003; Sebastiani and Perls 2012; Kirkland 2013). These specific manipulations are unlikely to be directly applicable in humans, but they may lead scientists in the right direction.

In addition, clinical interventions to delay aging have been proposed that involve interfering with chronic inflammation. In mice, the selective removal of senescent cells has been documented to lead to significant improvements in health, an intervention that many researchers believe could be clinically effective in people (Tchkonia et al. 2013). Some scientists contend that such interventions are sufficiently close to fruition that people alive today will benefit from them (Miller 2002; Martin et al. 2007; Butler et al. 2008; Sierra et al. 2009; Kirkland 2013; Tchkonia et al. 2013). Should we continue on this path of discovery?

In deciding whether and how much society should continue to invest in delayed aging, two specific questions arise. First, what are the social returns - in terms of health and spendingon continued investments in a "disease model" versus the returns on investments in delayed aging? Second, can society afford to invest in the accelerated development of interventions that extend healthy life, given fiscal uncertainties? In this article, we compare the future health and economic benefits - as well as the costsof continuing to prioritize the "disease model" with the benefits and costs of placing a new emphasis on delayed aging.

\section{ECONOMIC SCENARIOS OF DELAYED AGING}

We examined the economic benefits and costs of delayed aging, with a focus on the fiscal impact, in an article published in Health Affairs (Goldman et al. 2013). In what follows, we summarize these results. We specifically looked at the costs of major entitlement programs, specifically, Federal and State spending for Medicare and Medicaid, and Federal income support through old age, survivors, and disability insurance and supplemental security income. Economic outputs were aggregated into fiscally relevant variables using benefit rules for particular programs. Annual costs are given in constant 2010 dollars. All cumulative costs are discounted using a 3\% annual discount rate (Gold et al. 1996).

We developed four scenarios (one representing the status quo or baseline) and compared the health and medical spending they would involve. For each scenario, we conducted the simulation 50 times and averaged the outcomes. We assumed that all changes were accomplished at no additional cost relative to baseline, to allow us to focus on population benefits. Each scenario assumed that changes in mortality and disease processes occurred in the period 20102030. The scenarios also assumed that progress ceased after 2030, but that the effects of earlier changes continued to play out.

Two disease-specific scenarios were meant to represent optimistic developments in medical research, disease treatment, and improvements in behavioral risk factors. In other words, these scenarios assumed that by attacking dis- 
eases individually through treatments or systemically through behavior modification, the incidence of disease, and the impact of cases of disease would be reduced.

The fourth scenario (assuming delayed aging) is a hypothetical assessment of a successful effort to translate research on the biology of aging into therapeutic interventions that would reduce and compress both morbidity and mortality into a shorter period of time at the end of life (Olshansky et al. 2009). Unlike the delayed disease interventions in the two diseasespecific scenarios-which face diminishing returns because of competing causes of sickness and death in aging populations-the delayed aging scenario assumed that all fatal and disabling diseases were influenced simultaneously. Thus, this scenario represents what might best be thought of as a superefficient method of attacking the fatal and disabling diseases that are most prevalent at older ages - a form of primary prevention that would simultaneously influence all fatal and disabling diseases at once.

\section{Status Quo}

In the status quo (or baseline) scenario, we used the mortality forecasts for all-cause mortality in the intermediate projections of the Social Security Administration (The Board of Trustees of Federal Old-Age and Survivors Insurance and Federal Disability Insurance Trust Funds, see www.socialsecurity.gov/oact/TR/2011/tr2011 .pdf ). We did not change the incidence of disease. Heuristically, in this scenario, mortality improvements can be seen as the result of improved treatments for people with disease.

\section{Delayed Cancer}

In the first disease-specific scenario, we modified the status quo scenario by reducing the incidence of cancer over time. From 2010 to 2030, we phased in a linear $25 \%$ reduction in cancer incidence. We assumed that this change was accomplished at no additional Medicare cost relative to the baseline. Historical evidence suggests that there was a reduction of $1.3 \%$ in overall cancer incidence rates for men per year from
2000 to 2006 and a reduction of $0.5 \%$ for women per year from 1998 to 2006 (Jemal et al. 2010). Averaged over 20 years, these trends yield a range of reductions in cancer incidence of $10 \%$ to $26 \%$. Thus, our assumptions in this scenario were within the bounds of the observed trends. We assumed that the reduced incidence rate continued until the end of the simulation. To account for improvements in health before age 51 , the prevalence of chronic conditions in the incoming cohorts of 51-yr-olds was adjusted to match the prevalence for 44-yr-olds in the target year, as measured in the National Health Interview Survey.

\section{Delayed Heart Disease}

We modified the status quo scenario by reducing the incidence of heart disease over time. As was the case with cancer, we assumed a linear reduction in the incidence of $25 \%$ between 2010 and 2030, and no change thereafter (Kubo et al. 2003). And, again as in the delayed cancer scenario, we assumed that there was no additional Medicare cost, and we adjusted the prevalence of chronic conditions in the incoming cohorts.

\section{Delayed Aging}

We assumed that improvements in mortality and health started earlier in life than they did in the disease-specific scenarios. We assumed that the slope of the intrinsic mortality curvethat is, mortality from factors such as age, as opposed to exposure to external risks such as trauma or smoking-observed in 2000 for both men and women ages 15 to 50 would decline by $20 \%$ by 2050 . These hypothesized changes are consistent with research on the biology of aging, which suggests that the health benefits of delayed aging would begin at puberty-the time when mortality begins rising exponentially (de Magalhaes et al. 2005; Edlin and Stiglitz 2012).

\section{Delayed Aging with an Eligibility Fix}

We modeled a variant of the delayed aging scenario that included an adjustment to the eligi- 
bility age for Medicare and the normal retirement age for Social Security. Social Security provides a strong precedent for such a policy fix. The statutory full retirement age was raised in 1983 from 65 to 66, and the age will increase to 67 for people born in 1960 and later. Our "eligibility fix" consisted of a gradual increase in the eligibility age for Medicare from 35 to 38, and for Social Security from 67 to 68 (extending the Social Security amendments of 1983 , which mandated gradual increases in the retirement over a 22 -yr period starting in 2000 , for $\sim 10$ yr). In this scenario, people enrolled in Medicare Part A as soon as they were eligible to do so. The delayed aging scenario with the eligibility fix-because of the later official statutory retirement age-would result in more taxes collected during working years than in the original delayed aging scenario without an eligibility change, and less lifetime benefits paid because of the later start of retirement.

The impact of the changing rates of transition of disease and functional status can be seen in the change in average life-cycle characteristics. Life expectancy at age 51 in 2030 was $35.8 \mathrm{yr}$ in the status quo scenario, based on cur- rent Social Security Administration projections (see www.socialsecurity.gov/oact/TR/2011/tr 2011.pdf). It improved by $\sim 1 \mathrm{yr}$ in both the delayed cancer (36.9 yr) and delayed heart disease $(36.6 \mathrm{yr})$ scenarios. In the delayed aging scenario, however, it increased to $38.0 \mathrm{yr}$, an improvement of $2.2 \mathrm{yr}$ (Fig. 1) (Sullivan et al. 2013).

Under the status quo, the number of elderly people-those age 65 or older-in the United States more than doubled, increasing from 43 million in 2010 to 106 million in 2060. The scenarios of delayed cancer and delayed heart disease diverged little from the first scenario, leading to only $0.8 \%$ and $2.0 \%$ more elderly people in 2060, respectively. In contrast, the delayed aging scenario added $6.9 \%$ more elderly people. These demographic gains would occur quickly, with $6.1 \%$ more elderly Americans than in the status quo scenario after only $20 \mathrm{yr}$.

Of course, it matters whether these survivors would be healthy or disabled. In the status quo scenario, 31.0 million people age 65 or older were not disabled in 2010; the number was 75.5 million in 2060 (Fig. 2) (Manton et al. 1997; Freedman et al. 2004). In the dis-

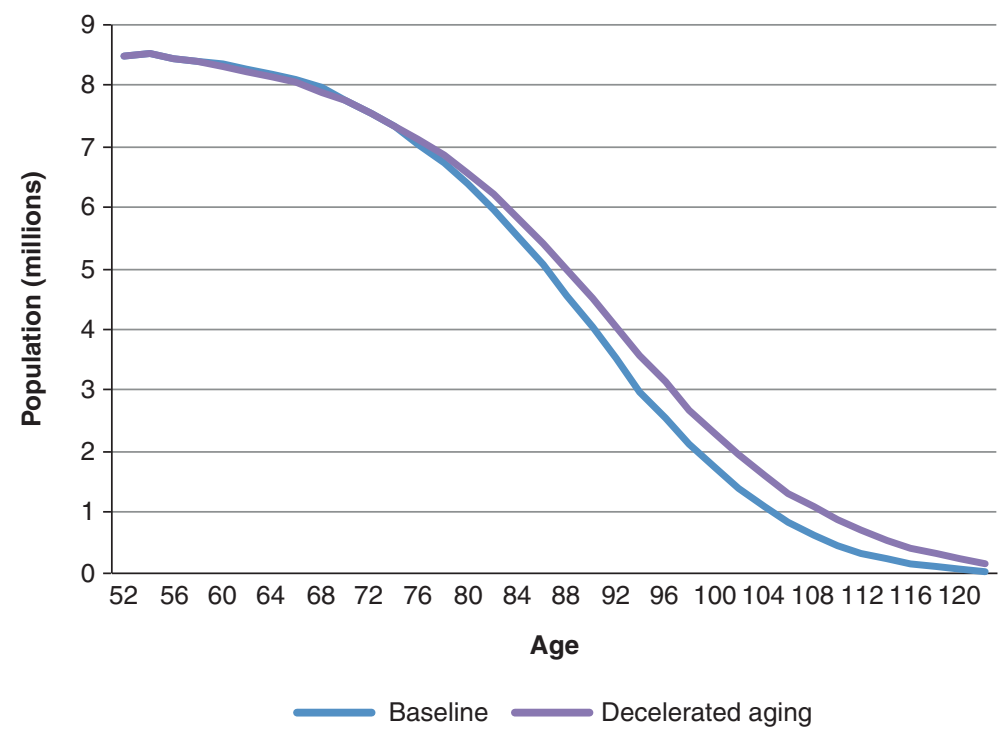

Figure 1. Survival in the 2030 cohort under baseline and delayed aging scenarios. Calculations are derived from the Future Elderly Model (see www.rand.org/pubs/research_briefs/RB9324/index1.html). 
D. Goldman

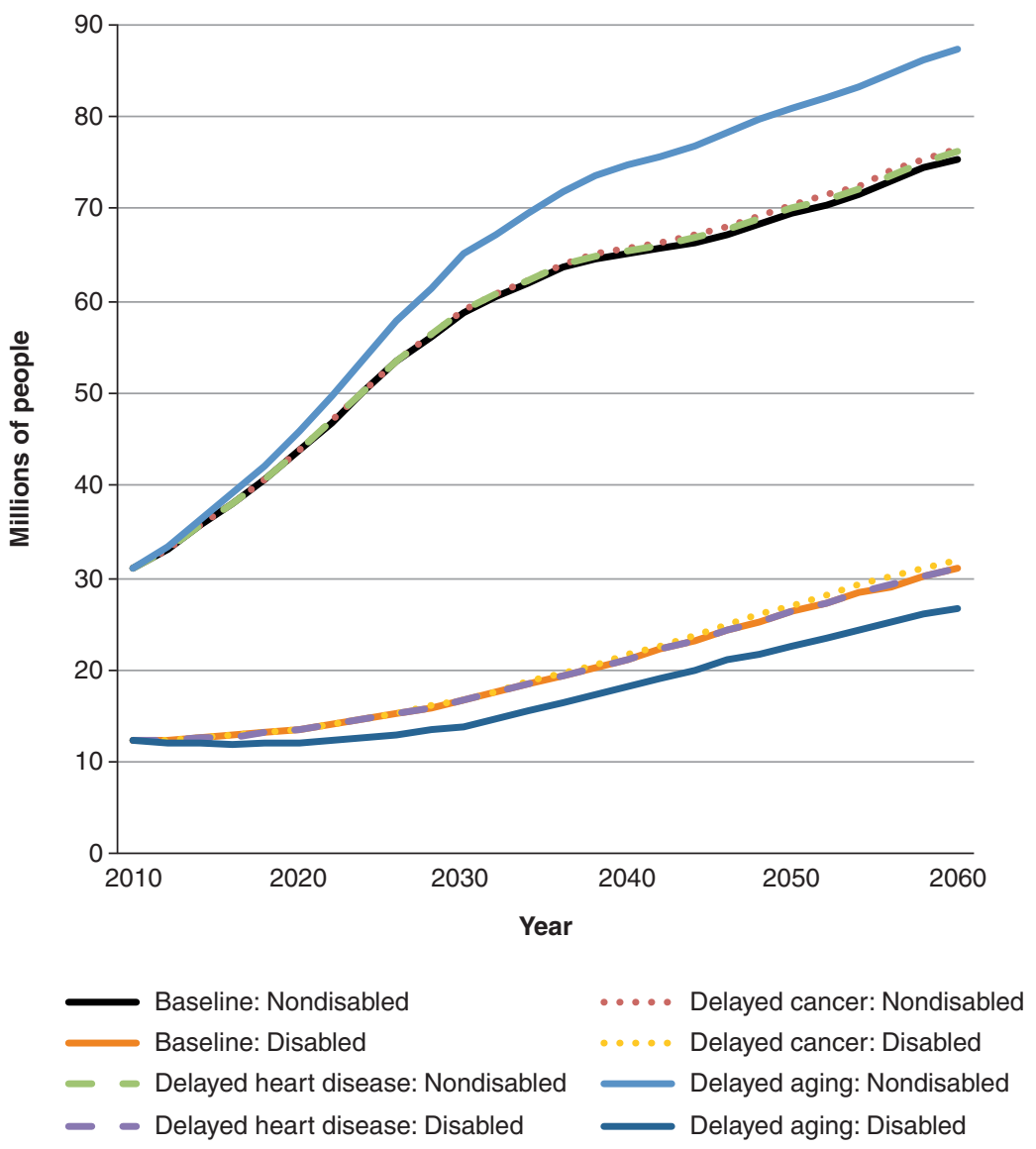

Figure 2. Millions of nondisabled and disabled elderly Americans in various scenarios, 2010-2060. The figure shows the number of elderly Americans (age 65 or older) projected to be either nondisabled or disabled according to the various medical progress scenarios. Disabled is defined as having one or more limitations in instrumental activities of daily living, having one or more limitations in activities of daily living, living in a nursing home, or a combination of the three. The delayed aging scenario resulted in a substantially higher percentage and number of nondisabled people than the delayed heart disease or delayed cancer scenario. Calculations are derived from the Future Elderly Model (see www.rand.org/pubs/research_briefs/RB9324/ index1.html).

ease-specific scenarios, there were very small increases in the number of nondisabled elderly people compared with the delayed aging scenario, in which there was a $15 \%$ increase from the status quo scenario.

These absolute numbers can also be translated into disability rates. Today, the share of the elderly United States population without disabilities is $\sim 72 \%$. In the status quo scenario, this share increased to $78 \%$ in 2026 but then declined to $71 \%$ in 2060 (Fig. 3) (Sullivan et al. 2013). This decline was caused by the lower all-cause mortality rates projected for the future, and the growing prevalence of health risks (such as obesity) among people entering the elderly group.

The disease-specific scenarios both had an effect nearly identical to the status quo scenario. In comparison, the delayed aging scenario yielded a larger share of nondisabled seniors in every year between 2010 and 2026, compared with the status quo scenario. Although the size 
The Economic Promise of Delayed Aging

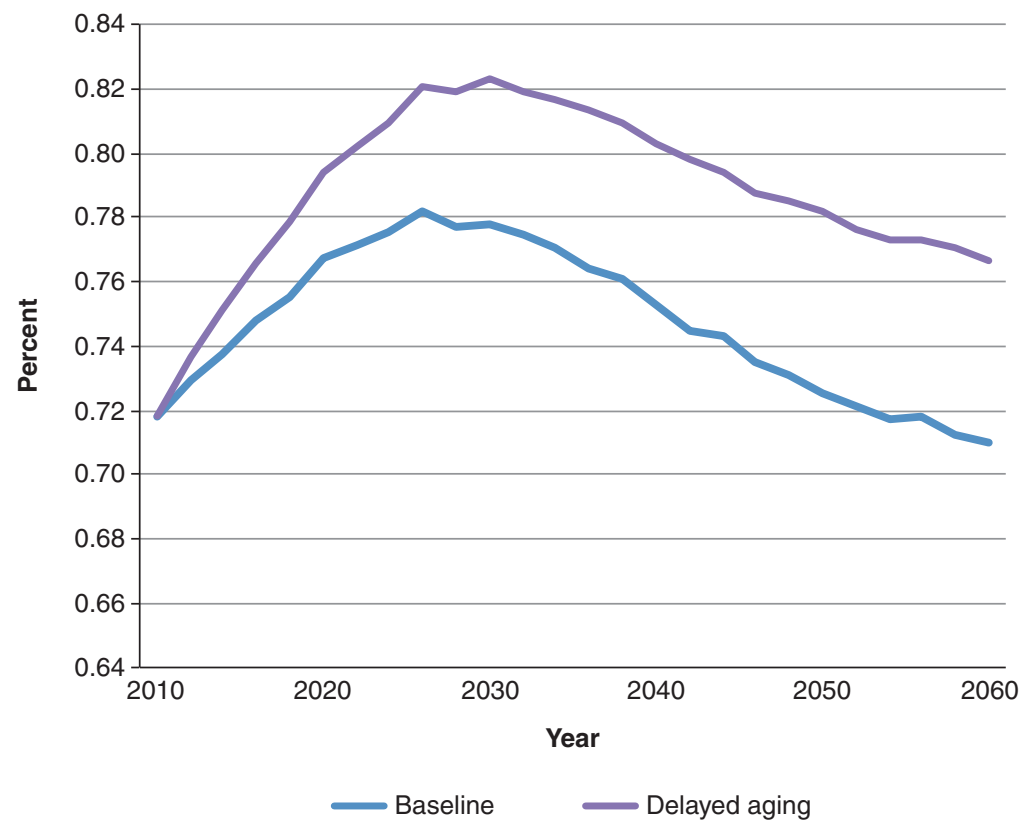

Figure 3. Fraction of 65 and older population without disability. Calculations are derived from the Future Elderly Model (see www.rand.org/pubs/research_briefs/RB9324/index1.html).

of the difference declined from 2030 to 2060 , during that 30 -yr period, an additional $5 \%$ of elderly people were nondisabled in the delayed aging scenario. Per capita Medicare spending was also lower in the delayed aging scenario than in the status quo scenario.

On the population level, the aggregate costs show the fiscal strain imposed by delayed aging (Fig. 4). In that scenario, more elderly people were alive. Consequently, more people qualified for entitlement programs, and costs were higher. In 2060, spending in the delayed aging scenario was $\$ 295$ billion more than in the status quo scenario. In contrast, the delayed cancer scenario led to only a modest increase, and the delayed heart disease scenario brought spending below the level in the status quo scenario.

The gap in income support was also considerable. Spending beyond that in the status quo scenario was relatively low in the disease-specific scenarios (Fig. 5). In comparison, it climbed to around $\$ 125$ billion in the delayed aging scenario by 2055 . Delayed aging would add nearly $\$ 420$ billion to the entitlement deficit in the status quo scenario in $2060,70 \%$ of which would come from increased outlays for Medicare and Medicaid.

Figure 6 shows the fiscal effects of the four main scenarios as well as the effect of delayed aging with the eligibility fix to Medicare and Social Security described above. The eligibility fix would more than offset the additional costs of delayed aging relative to the costs of the status quo scenario.

\section{THE VALUE OF DELAYED AGING}

Our results show that shifting the focus of medical investment to delayed aging would lead to a set of desirable, but economically challenging, circumstances. The potential gains are significant. Although the disease model has reduced mortality from lethal conditions dramatically in the past century, its influence is now waning because of competing risks. As people live longer, they are more likely to fall victim to multiple diseases. Our simulations of reduced incidence of heart disease and cancer suggested incrementally smaller gains in longevity going forward. 
D. Goldman

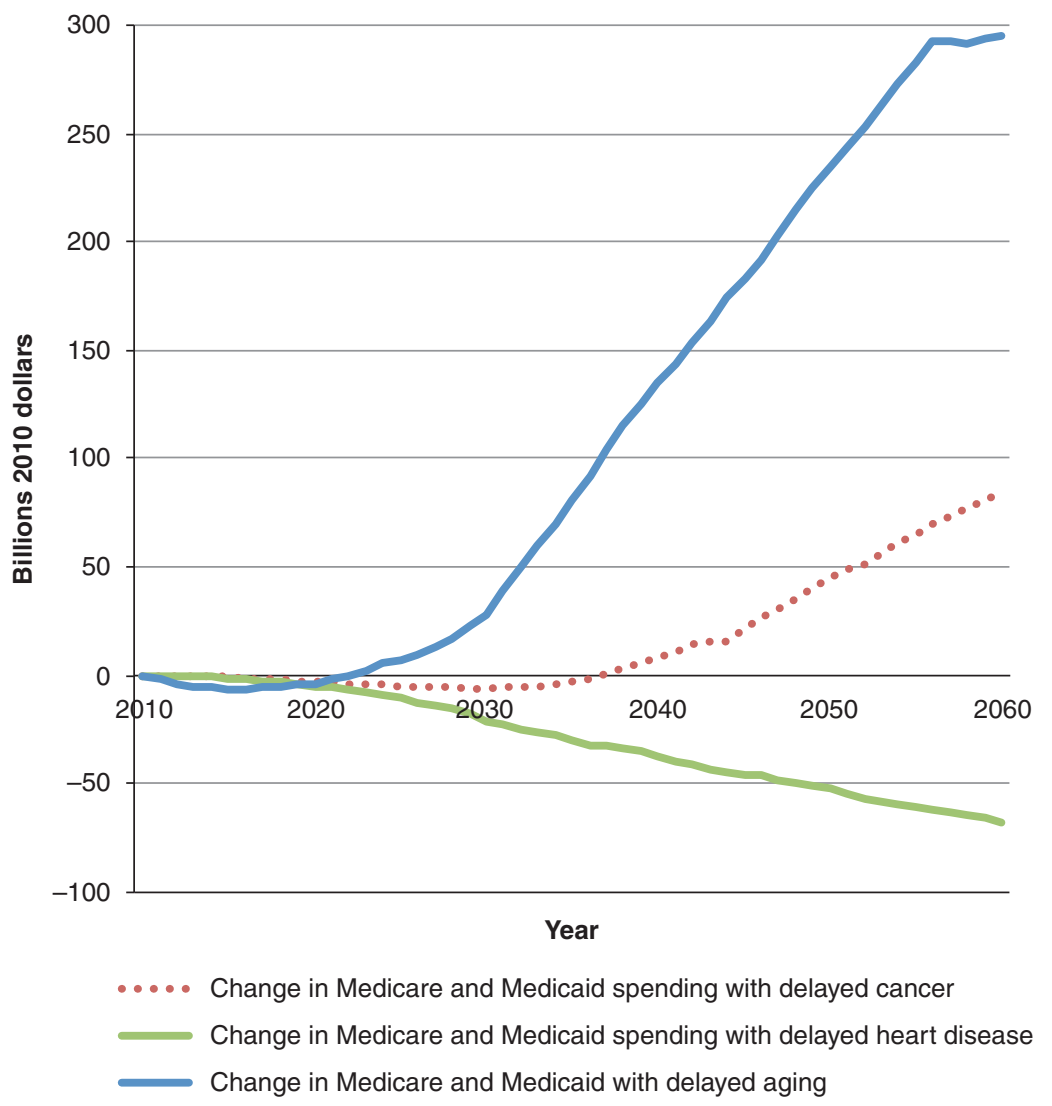

Figure 4. Change in Medicare and Medicaid spending on health care in various scenarios compared with status quo, billions of dollars, 2010-2060. All spending is in 2010 dollars. The figure shows per period (nondiscounted) projected spending on Medicare and Medicaid under various medical progress scenarios, relative to the status quo scenario for Americans aged 51 or older. Spending is much higher in the delayed aging scenario because of the larger increase in the total population, even though per period costs for Medicare are lower. Calculations are derived from the Future Elderly Model (see www.rand.org/pubs/research_briefs/RB9324/ indexl.html).

The medical costs of treating these diseases independently would rise but, for example, would produce only a 3.2-yr increase in life expectancy for 65-yr-olds from 2010 to 2060 (The Board of Trustees of Federal Old-Age and Survivors Insurance and Federal Disability Insurance Trust Funds, see www.socialsecurity.gov/oact/TR/ 2011/tr2011.pdf).

Recent research has shown that the decadeslong improvement in the functional status of older Americans halted in 2002 (Lakdawalla et al. 2004; Crimmins and Beltran-Sanchez 2011). This suggests that many of the historical drivers of better health in the elderly may no longer work. Declining disability buttresses the case for research on slowing aging by compressing morbidity and extending healthy life, which would provide an adequate workforce for producing the goods and services that the future aging society would use, and would yield direct benefits to those older people who remain socially engaged.

Still, the fact remains that longer lives would mean greater fiscal burdens for Social Security and other income support programs and increased Medicare and Medicaid expenditures, even as per capita medical costs declined. An unequivocal answer to the question of whether 


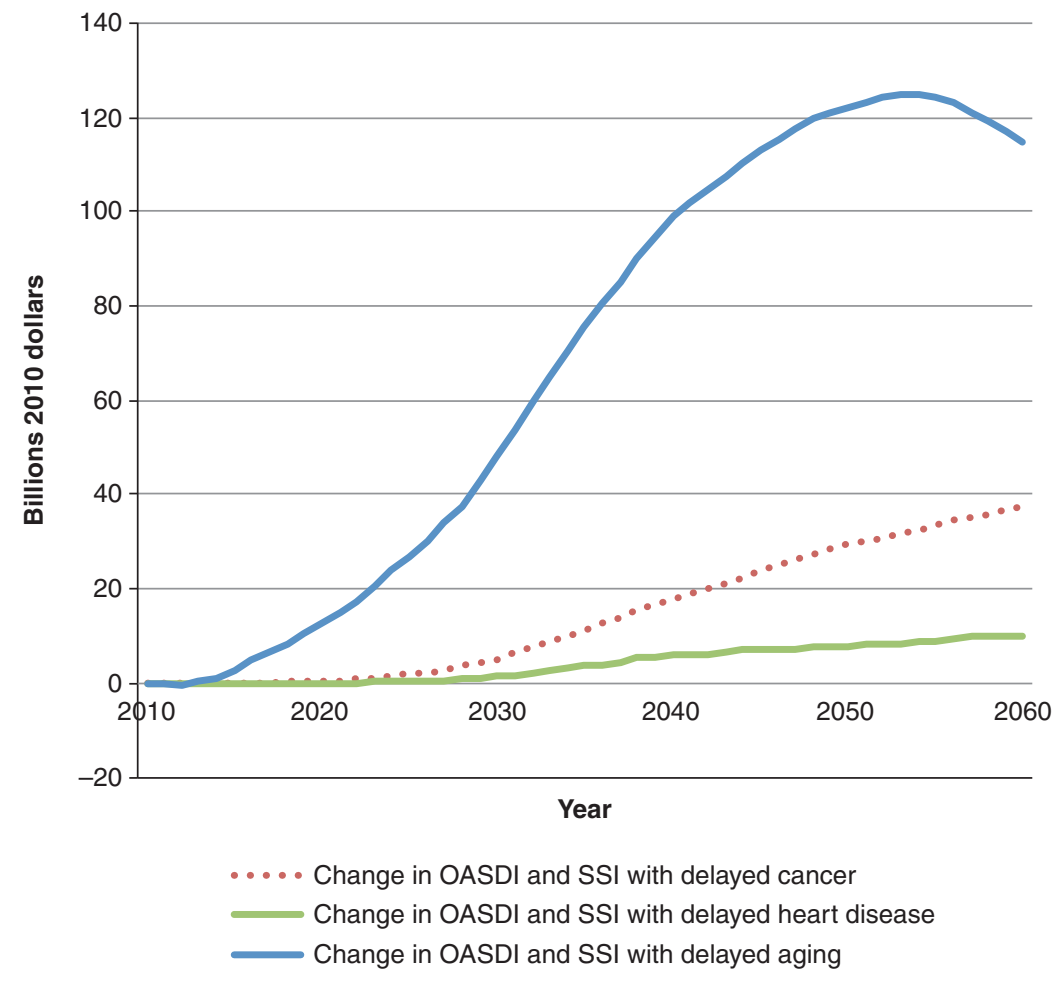

Figure 5. Change in income support spending in various scenarios compared with status quo, billions of dollars, 2010-2060. All spending is in 2010 dollars. The figure shows per period (nondiscounted) projected spending on income support under various medical progress scenarios, relative to the status quo scenario. Income support includes all Old-Age and Survivors Insurance, Social Security Disability Insurance (OASDI) and Supplemental Security Income (SSI) spending on Americans age 51 or older. Spending is much higher under the delayed aging scenario because of the larger increase in the total population. Calculations are derived from the Future Elderly Model (see www.rand.org/pubs/research_briefs/RB9324/index1.html).

the current focus of medical research and investment should be shifted from the disease model to delayed aging depends on whether the potential gains could be realized and the adverse consequences allayed. One way to reflect on the future gains is to look at the presented discounted value of all the additional, qualityadjusted life-years that arise from delayed aging relative to the status quo. These can then be valued using a conservative metric such as $\$ 100,000$ per life-year. Doing so yields a social benefit related to delayed aging of $\sim \$ 7.1$ trillion, without even considering the cognitive benefits that could arise from these interventions (Christensen et al. 2013).

Given the large social return, the question then becomes how we accommodate these changes fiscally. Several policy measures might achieve fiscal balance; we show one involving eligibility changes, but a full evaluation of the options is beyond the scope of this research. However, we note here one benefit of delayed aging that might enlarge the set of possibilities. With people staying healthy until a much later age, it might be more feasible to justify raising the eligibility age for public programs for seniors. Arguments against doing so often note that life expectancy increases in lower socioeconomic groups have lagged far behind those in better-off groups (Ketcham and Simon 2008; Kindig and Cheng 2013). A future in which delayed aging increased the health of all socioeconomic groups would make these increases in eligibility ages more palatable. 
D. Goldman

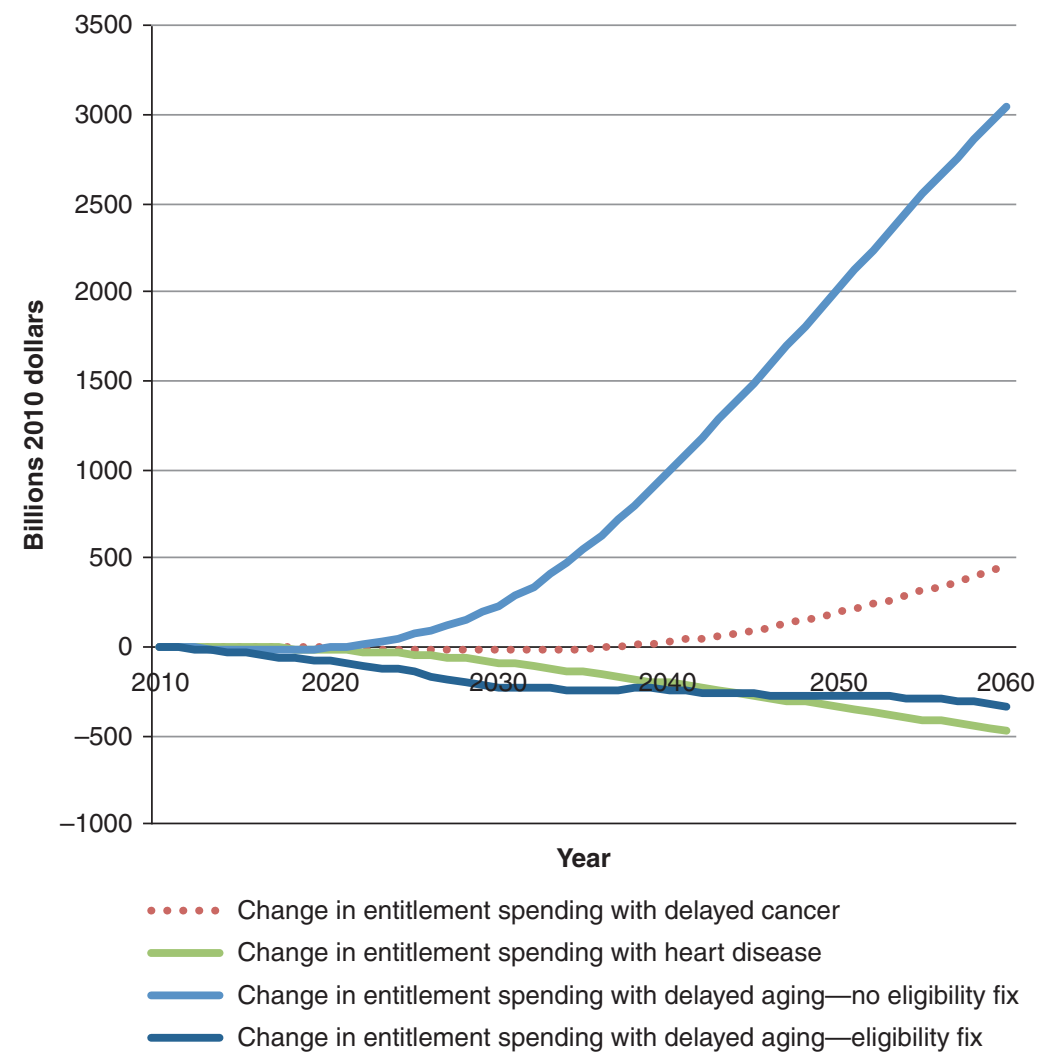

Figure 6. Change in major entitlement spending in various scenarios compared with status quo, billions of dollars, 2010-2060. All spending is in 2010 dollars. The figure shows the cumulative fiscal impact of spending on Medicare, Medicaid, Old-Age and Survivors Insurance, Social Security Disability Insurance (OASDI), and Supplemental Security Income (SSI) (discounted at 3\%) of various medical progress scenarios relative to the status quo scenario. The fix is a gradual increase in the eligibility ages for Medicare and Social Security. The inclusion of the eligibility fix would result in no additional entitlement spending relative to that in the status quo scenario, despite much larger increases in the older population. Calculations are derived from the Future Elderly Model (see www.rand.org/pubs/research_briefs/RB9324/index1.html).

\section{CONCLUSION}

It is clear that competing health risks limit the impact of major clinical breakthroughs for specific diseases. In other words, making progress against one disease means that another one will eventually emerge in its place. However, evidence suggests that if aging is delayed, all fatal and disabling disease risks would be lowered simultaneously.

The potential economic benefits of delayed aging are enormous. We find that realizing the promise of the current biological models might net society $>\$ 7$ trillion in net benefits. (This windfall may explain why the private sector has become increasingly keen to research these mechanisms.) The major challenges of delayed aging appear to be of a fiscal nature, but they are manageable. The benefits to society of delayed aging would accrue rapidly and would extend to all future generations. Investing in research to delay aging should become a priority.

More generally, innovations to prevent disease have enormous economic salience, even at older ages. However, our current health system rewards treatment at the expense of prevention. This has likely led to dramatic underinvestment in forestalling disease onset. Clearly, there is a 
public role to play in tilting the playing field back from treatment to prevention, and as evidence presented here indicates, delayed aging could very well become the most efficient method of primary prevention available.

\section{REFERENCES}

Bhattacharya J, Cutler DM, Goldman DP, Hurd MD, Joyce GF, Lakdawalla DN, Panis CW, Shang B. 2004. Disability forecasts and future Medicare costs. Front Health Policy Res 7: 75-94.

Butler RN, Miller RA, Perry D, Carnes BA, Williams TF Cassel C, Brody J, Bernard MA, Partridge L, Kirkwood T, et al. 2008. New model of health promotion and disease prevention for the 21st century. BMJ 337: a399.

Christensen K, Thinggaard M, Oksuzyan A, Steenstrup T, Andersen-Ranberg K, Jeune B, McGue M, Vaupel JW. 2013. Physical and cognitive functioning of people older than 90 years: A comparison of two Danish cohorts born 10 years apart. Lancet 382: 1507-1513.

Crimmins EM, Beltran-Sanchez H. 2011. Mortality and morbidity trends: Is there compression of morbidity? $J$ Gerontol B Psychol Sci Soc Sci 66: 75-86.

Cutler DM. 2001. Declining disability among the elderly. Health Affairs 20: 11-27.

Experts in Chronic Myeloid Leukemia. 2013. The price of drugs for chronic myeloid leukemia (CML) is a reflection of the unsustainable prices of cancer drugs: From the perspective of a large group of CML experts. Blood 121: 4439-4442.

Freedman VA, Crimmins E, Schoeni RF, Spillman BC, Aykan H, Kramarow E, Land K, Lubitz J, Manton L, Martin LG, et al. 2004. Resolving inconsistencies in trends in old-age disability: Report from a technical working group. Demography 41: 417-441.

Fries JF. 1980. Aging, natural death, and the compression of morbidity. N Engl J Med 303: 130-135.

Fries JF, Koop CE, Beadle CE, Cooper PP, England MJ, Greaves RF, Sokolov JJ, Wright D. 1993. Reducing health care costs by reducing the need and demand for medical services. N Engl J Med 329: 321-325.

Gold M, Siegel J, Russell L, Weinstein M. 1996. Cost-effectiveness in health and medicine. Oxford University Press, New York.

Goldman DP, Philipson T. 2014. Five myths about cancer care in America. Health Aff (Millwood) 33: 1801-1804.

Goldman DP, Shang B, Bhattacharya J, Garber AM, Hurd M, Joyce GF, Lakdawalla DN, Panis C, Shekelle PG. 2005. Consequences of health trends and medical innovation for the future elderly. Health Aff (Millwood) 24: W5-R5W5-R17.

Goldman DP, Cutler D, Rowe JW, Michaud PC, Sullivan J, Peneva D, Olshansky SJ. 2013. Substantial health and economic returns from delayed aging may warrant a new focus for medical research. Health Aff (Millwood) 32: 1698-1705.

Hsu T, Ennis M, Hood N, Graham M, Goodwin PJ. 2013. Quality of life in long-term breast cancer survivors. J Clin Oncol 31: 3540-3548.
Hulsegge G, Picavet HS, Blokstra A, Nooyens AC, Spijkerman AM, van der Schouw YT, Smit HA, Verschuren WM. 2014. Today's adult generations are less healthy than their predecessors: Generation shifts in metabolic risk factors: The Doetinchem cohort study. Eur J Prev Cardiol 21: 1134-1144.

Jemal A, Siegel R, Xu J, Ward E. 2010. Cancer statistics, 2010. CA Cancer J Clin 60: 277-300.

Ketcham JD, Simon KI. 2008. Medicare Part D's effects on elderly patients' drug costs and utilization. Am J Manag Care 14: SP14-SP22.

Kindig DA, Cheng ER. 2013. Even as mortality fell in most US counties, female mortality nonetheless rose in 42.8 percent of counties from 1992 to 2006. Health Aff (Millwood) 32: 451-458.

Kirkland JL. 2013. Translating advances from the basic biology of aging into clinical application. Exp Gerontol 48: $1-5$.

Kubo M, Kiyohara Y, Kato I, Tanizaki Y, Arima H, Tanaka K, Nakamura H, Okubo K, Iida M. 2003. Trends in the incidence, mortality, and survival rate of cardiovascular disease in a Japanese community: The Hisayama study. Stroke 34: 2349-2354.

Lakdawalla DN, Bhattacharya J, Goldman DP. 2004. Are the young becoming more disabled? Health Aff (Millwood) 23: $168-176$.

Lakdawalla DN, Sun EC, Jena AB, Reyes CM, Goldman DP, Philipson TJ. 2010. An economic evaluation of the war on cancer. J Health Econ 29: 333-346.

Lipton RB, Hirsch J, Katz MJ, Wang C, Sanders AE, Verghese J, Barzilai N, Derby CA. 2010. Exceptional parental longevity associated with lower risk of Alzheimer's disease and memory decline. J Am Geriatr Soc 58: 1043-1049.

Lowsky DJ, Olshansky SJ, Bhattacharya J, Goldman DP. 2013. Heterogeneity in healthy aging. J Gerontol A Biol Sci Med Sci 69: 640-649.

Manton KG, Corder L, Stallard E. 1997. Chronic disability trends in elderly United States populations: 1982-1994. Proc Natl Acad Sci 94: 2593-2598.

Martin GM, Bergman A, Barzilai N. 2007. Genetic determinants of human health span and life span: Progress and new opportunities. PLoS Genet 3: e125.

Miller RA. 2002. Extending life: Scientific prospects and political obstacles. Milbank Q 80: 155-174.

Olshansky SJ, Goldman DP, Zheng Y, Rowe JW. 2009. Aging in America in the twenty-first century: Demographic forecasts from the MacArthur Foundation Research Network on an Aging Society. Milbank Q 87: 842-862.

Sebastiani P, Perls TT. 2012. The genetics of extreme longevity: Lessons from the New England Centenarian Study. Front Genet 3: 277.

Shekelle PG, Ortiz E, Newberry SJ, Rich MW, Rhodes SL, Brook RH, Goldman DP. 2005. Identifying potential health care innovations for the future elderly. Health Aff (Millwood) 24: W5-R67-W5-R76.

Sierra F, Hadley E, Suzman R, Hodes R. 2009. Prospects for life span extension. Annu Rev Med 60: 457-469.

Stevens W, Philipson TJ, Khan ZM, MacEwan JP, Linthicum MT, Goldman DP. 2015. Cancer mortality reductions were greatest among countries where cancer care spend- 


\section{Goldman}

ing rose the most, 1995-2007. Health Aff (Millwood) 34: $562-570$.

Sullivan J, Goldman D, Michaud PC, Peneva D. 2013. Online supplement for "Attacking diseases by slowing aging: Health and economic implications." University of Southern California, Los Angeles.

Sun E, Jena AB, Lakdawalla D, Reyes CM, Philipson T, Goldman D. 2010. The contributions of improved therapy and earlier detection to cancer survival gains, 1988-2000. Forum Health Econ Policy 13: 1-20.
Tatar M, Bartke A, Antebi A. 2003. The endocrine regulation of aging by insulin-like signals. Science 299: 1346-1351.

Tchkonia T, Zhu Y, van Deursen J, Campisi J, Kirkland JL. 2013. Cellular senescence and the senescent secretory phenotype: Therapeutic opportunities. J Clin Invest 123: 966-972.

Vergara M, Smith-Wheelock M, Harper JM, Sigler R, Miller RA. 2004. Hormone-treated snell dwarf mice regain fertility but remain long lived and disease resistant. $J$ Gerontol A Biol Sci Med Sci 59: 1244-1250. 


\title{
$\&_{\mathrm{CSH}}^{\infty} \&$ Cold Spring Harbor

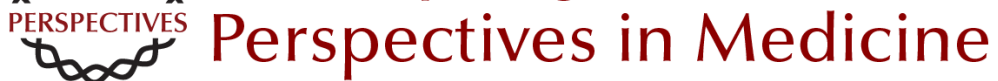

\section{The Economic Promise of Delayed Aging}

\author{
Dana Goldman
}

Cold Spring Harb Perspect Med 2016; doi: 10.1101/cshperspect.a025072 originally published online December 18, 2015

\section{Subject Collection Aging}

Personalized Financial Planning Using Applied Genetics

S. Jay Olshansky, Bradley Willcox, Kirk Ashburn, et al.

Biological Restraints on Indefinite Survival Jan Vijg and Steven N. Austad

The Role of the National Institute on Aging in the Development of the Field of Geroscience Felipe Sierra and Ronald A. Kohanski

The Funding Channels of Geroscience Stephanie Lederman

\section{Evolutionary Approaches in Aging Research Melissa Emery Thompson}

Interventions for Human Frailty: Physical Activity as a Model

Linda P. Fried

How Research on Human Progeroid and

Antigeroid Syndromes Can Contribute to the

Longevity Dividend Initiative

Fuki M. Hisama, Junko Oshima and George M. Martin

Articulating the Case for the Longevity Dividend S. Jay Olshansky
Funding Life-Extension Research Mehmood Khan

Influence of Aging Science on Global Wealth Management Michael Hodin

International Gains to Achieving Healthy

Longevity Andrew Scott, Julian Ashwin, Martin Ellison, et al.

From Life Span to Health Span: Declaring

"Victory" in the Pursuit of Human Longevity S. Jay Olshansky

Crowdfunding and Crowdsourcing of Aging

Science Keith Comito

Inhibition of the Mechanistic Target of Rapamycin (mTOR) -Rapamycin and Beyond Dudley W. Lamming

The Emergence of Geroscience as an Interdisciplinary Approach to the Enhancement of Health Span and Life Span Felipe Sierra

The Economic Promise of Delayed Aging Dana Goldman

For additional articles in this collection, see http://perspectivesinmedicine.cshlp.org/cgi/collection/ 